\title{
The Heritability Challenge to Evolution and Materialism: An Opening for Religious Perspectives
}

\author{
Ted Christopher \\ 71 Azalea Road, Rochester, NY, 14620, USA \\ Email: tchrist7@rochester.rr.com
}

How to cite this paper: Christopher, T. (2018). The Heritability Challenge to Evolution and Materialism: An Opening for Religious Perspectives. Open Journal of Philosophy, 8, 355-364. https://doi.org/10.4236/ojpp.2018.84025

Received: June 27, 2018

Accepted: August 5, 2018

Published: August 8, 2018

Copyright $\odot 2018$ by author and Scientific Research Publishing Inc. This work is licensed under the Creative Commons Attribution International License (CC BY 4.0).

http://creativecommons.org/licenses/by/4.0/

\section{cc (i) Open Access}

\begin{abstract}
There are under-appreciated, serious behavioral challenges to science's understanding of life and its evolution. The general challenge to that understanding, though, has unfolded in the form of pervasive failures in the search for the DNA origins of many heritable characteristics. Science has placed enormous faith in the presumed workings of DNA, including of course as a foundation for evolution. The stunning inability to identify the DNA bases for many heritable characteristics amongst humans-sometimes termed the missing heritability problem-is a big challenge to the largely unquestioned, biological vision. This situation is discussed herein along with its possible implications for religious perspectives.
\end{abstract}

\section{Keywords}

Religion and Science, Evolution, Religion, Genetics, Materialism

\section{Introduction}

It is difficult to overstate the expectations surrounding DNA. Perhaps the current unquestioned consensus was given succinctly by Craig Venter in answering the question "What is life?" with the expression, "DNA-driven biological machines" (Venter, 2014: p. 6). Under-appreciated challenges to this belief have been apparent, though, in particular in the behavioral realm. Some simple examples can be found including observations of the innate differences between monozygotic (identical) twins, prodigious intellectual abilities, and the transgender phenomena (Christopher, 2017a; Christopher, 2017b).

A more elemental statement on the scientific perspective of life was provided in a May 2017 Scientific American article. That article presents recent develop- 
ments in technologies used to observe the dynamics of molecules (involving x-ray based "molecular movies"). In it the authors, Petra Fromme and John C. H. Spence, provided motivation for their own work with a quote from the late prominent physicist Richard Feynman in which he had said, "Everything that living things do can be understood in terms of the jigglings and wigglings of atoms" (Fromme \& Spence, 2017). This is the basis for scientific materialism and it underlies the essentially uncontested claim that "Biology [is] physics" (Mukherjee, 2016: p. 142). Science's absolute confidence in materialism (or physicsism) is also the foundation for the ongoing intellectual parade against religious perspectives on life.

DNA has a very big role within materialism. It is supposed to provide the basis for inheritance and the associated variability, phenomena that Charles Darwin never understood (Mayr, 2001: p. 89). Ernst Mayr provided modern biology's answer:

An understanding of the nature of this variability was finally made possible, after 1900, by advancements in genetics and molecular biology. One can never fully understand the process of evolution unless one has an understanding of the basic facts of inheritance, which explain variation. Therefore the study of genetics [and the encompassing DNA] is an integral part of the study of evolution. But only the heritable part of variation plays a role in evolution (Mayr, 2001: p. 89).

Thus DNA is supposed to provide the codes (or blueprints) for organisms. As such it should define their innate differences, both in a gross interspecies sense as well as a more intimate intra-species sense. A reminder here is that genes consist of the subset of DNA which provide definitions for the construction of the body's protein molecules.

One of the key functions of DNA is believed to be in determining innate behavioral differences. This is supposed to be true in an intra-species sense-and thus the field of behavioral genetics-but it is also believed to be critical in a more gross evolutionary sense. Mayr wrote that:

There are reasons to believe that behavioral shifts have been involved in most evolutionary innovations, hence the saying "behavior is the pacemaker of evolution." Any behavior that turns out to be of evolutionary significance is likely to be reinforced by the selection of genetic determinants for such behavior (known as the Baldwin effect) (Mayr, 2001: p. 137).

Thus DNA should establish a substantial basis for the large spectrum of innate inclinations we can see in our daily lives. This includes providing a gross explanation for personality differences, including more particularly those found between same-sex (non-monozygotic twin) siblings. It is here that modern genetics is confidently committed to identifying the specific DNA codes that produce such differences, including of course some very significant ones. Beyond the previously identified singular code segments-like the Y chromosome and codes 
responsible for some disease conditions-the ongoing much more comprehensive genetic searches should be filling out the understanding of our innate particulars.

Conveniently, it turns out that homosapiens have been referred to by geneticists as a "small species" since there is relatively little genetic variation amongst us, and such limited variation is typical of a species with a small population (Pinker, 2002: pp. 142-143). That lack of genetic variation followed from our having been a small species not too long ago as we struggled through a difficult period. An insufficient amount of time has since elapsed for that limited DNA variation to expand much (unlike our population numbers). Thus it turns out that any two human beings are about $99.9 \%$ identical in terms of their DNA blueprints, which translates to being different in about 3 million bases or letters (Green, 2013; Kingsley, 2009; Schafer, 2006). It is also worth noting that even amongst this $0.1 \%$ variable portion of our genomes, there could be plenty of irrelevant junk (Zimmer, 2015). Thus, amongst the oft-cited three billion nucleotides there is a small subset of our DNA that should be home to our heritable differences.

It is here in the search for our genetic determinants that science hopes to provide help for difficult conditions, as well as to confirm some of DNA's evolutionary role. On this point consider the following excerpts from a 2003 Scientific American interview with Nobel laureate James D. Watson (Watson, 2003):

SA: [i]n a century, we went from rediscovering Mendel's laws and identifying chromosomes as agents of heredity to having the human genome largely worked out. Finding the double helix drops neatly in the middle of that span. How much, with respect to DNA, is left for us to do? Are there still great discoveries to be made, or is it just filling in details?

And then after some speculation:

Watson: [relevant research] seems to moving pretty fast. You don't really want to make a guess, but I'd guess that over the these next 10 years, the field will be pretty played out. A lot of very good people are working on it. We have the tools. At some stage, the basic principles of genetics will be known be in terms of gene functioning, and then we'll be able to apply that more to [more difficult] problems such as how the brain works.

Finally, Scientific American asked Watson, "[i]f you were starting out as a researcher now". Watson interjected, "I'd be working on something about connections between genes and behavior. You can find genes for behaviors...”.

This optimism reflects the confidence in the genetic model. The problem, though, is that there have been a number of under-appreciated challenges to the DNA-logic and now more broadly, the "moving pretty fast" search has been an "absolutely beyond belief" failure over the past decade (Wade, 2008; Balter, 2017). If DNA fails to determine our individual specifics then that would constitute a huge setback for science. Such a failure would also generally threaten 
the modern intellectual fixture, materialist-based evolution, and could also open the door to religious explanations.

\section{Some Under-Appreciated Behavioral Challenges}

As the author previously pointed out, there are a number of accepted behavioral conundrums that are very difficult to explain with the modern vision of life. Whether in the form of prodigies who appear to hit the pavement running in adult-focused and -learned ways, or in the form of transgender kids who appear to innately have the opposite sex's agenda plugged into them and moreover seem to know "that they had been born into the wrong gender from childhood" (Landau, 2009). Biology seems to have neglected the challenges posed by little kids "knowing things [that were] never learned" (Treffert, 2010) or young boys talking about their plans in which "I'm a mommy [and] I'll adopt my babies, but I'll have boobies to feed them and I'll wear a bra, dresses, skirts, and high-heeled shoes" (Solomon, 2012: pp. 605-606). Readers can compare such observations to Mayr's claim that " $[t]$ here is not a single Why? question in biology that can be answered adequately without consideration of evolution" (Mayr, 2003: p. xiii). Apparently if you bracket yourself down to science's vision of life then everything makes sense.

But analogous conundrums can be found outside of the not-too-rare extraordinary human behavioral realms. One such area is with bird migrations. Migratory birds demonstrate an innate knowledge of migratory routes and this scientifically implies a DNA-based explanation. But how plausible is it really for a large molecule-deoxyribonucleic acid (DNA) - to have been shaped by natural selection to encode for the making of a brain equipped with migratory maps? On this point even James Watson expressed astonishment (Watson, 2003).

Continuing here it is also difficult to imagine how an elemental DNA dynamic could have formed complex instinctive behavioral tendencies. As Rupert Sheldrake pointed out:

[g]enes are not selfish and ruthless, as if they contained gangster homunculi. Nor are they plans or instructions for organisms. They merely code for the sequences of amino acids in protein molecules (Sheldrake, 2012: p. 163).

Nonetheless, a number of species exhibit an unlearned or instinctive fear of snakes and it is a challenge to imagine discrete changes in the DNA code resulting in an automatic ability to become alarmed over the sight of a snake. As non-infants most of us quite effortlessly see a visual field full of particular objects (including trees, dogs, houses, garbage cans, clouds, etc.), and that process is built upon our past efforts to learn the appearances of those objects. This built-in instinctive fear is possibly analogous to the peculiar phobias that show up with some young children.

\section{Genetics' Bind}

If science's materialist-based evolutionary perspective is accurate then patterns 
of DNA should be responsible for the variations we observe in human behavioral tendencies. Apparently under-appreciated by biologists, though, is that there have been officially-verified problems with that line of reasoning. Before considering those, though, it is worth considering the inheritance footing of some behavioral tendencies. This footing was nicely captured by Steven Pinker who wrote that:

schizophrenia is highly concordant within pairs of identical twins [about $50 \%$ of the time when one is affected so is the other twin], who share all of their DNA and most of their environment, but far less concordant within pairs of fraternal twins, who share only half of their [variable] DNA ... and most of their environment. The trick question could be asked-and would have the same answer-for virtually every cognitive and emotional disorder or difference ever observed. Autism, dyslexia, language delay, language impairment, learning disability, left-handedness, major depressions, bipolar illness, obsessive-compulsive disorder, sexual orientation, and many other conditions run in families, are more concordant in identical than in fraternal twins, are better predicted by people's biological relatives than by their adoptive relatives, and are poorly predicted by any measurable feature of the environment (Pinker, 2002: p. 46).

Thus the variation in the innate specifics of individuals' shows up in (biological) parent-connected patterns. Variations in innateness are often pretty obvious, whilst the inheritance-packaging of innateness is not so obvious (except physically), but comes thru in formal studies. Pinker's statement does, though, appear to shortchange the environmental contributions to schizophrenia.

On the other hand, there are at least three problems with the logic of behavioral genetics. First, there are large variations present in identical twins (who share their DNA blueprints). The degree of behavioral agreement between identical twins is often only around 50 percent, but in the case of male exclusive homosexuality it is only 20 - 30 percent (Collins, 2010: pp. 204-205). Second, as alluded to above alternative explanations involving environmental influences have been observed to have limited support. Outside of specific fears and a few familial positions (like political affiliation) growing up in a family appears to contribute little to an individual's inclinations (this really comes across in adoption studies). The import of these two challenges are nicely captured in another Pinker quote, "identical twins are 50 percent similar [behaviorally] whether they grow up together or apart” (Pinker, 2002: p. 381).

A third challenge to genetics' perspective is an indirect but rather gross one. Behavioral genetics is supposed to operate thru the influence of genes (or more generally DNA) on an individual's brain. Observations of individuals with gross brain deficiencies raises questions about such reasoning, though. In a 1980 Science article some observations by a neurologist John Lorber with regards to a group of patients who were missing large portions of their brains was described (Lewin, 1980). The article reported that a number of patients whom on the one 
hand only had roughly 5 percent of normal brain volume, but on the other hand appeared to function normally (others in this category were as expected severely disabled). Amongst, this group Lorber reported that:

[t]here is a young student at [Sheffield University] who has an IQ of 126, has gained a first-class honors degree in mathematics, and is socially completely normal. And yet the boy has virtually no brain.

Findings like these seem to be selectively ignored by science and they seriously challenge genetic reasoning as well as materialism.

The direct problem facing genetics, though, has been the unfolding failure to identify the DNA determinants for behavioral-as well as disease-inclinations. In a 2014 review of another "breakthrough" in the genetics of intelligence (purporting to account for a possible 1 percent in the variance of human's innate intelligence), John Horgan-Scientific American's resident contrarian-pointed out that in a 2012 Behavioral Genetics editorial it had been stated that:

[t]he literature on candidate gene associations is full of reports that have not stood up to rigorous replication. This is the case both for straightforward main effects and for candidate gene-by-environment interactions...As a result the psychiatric and behavioral genetics literature has become confusing and it now seems likely that many of the published findings of the last decade are wrong or misleading and have not contributed to real advances in knowledge (Horgan, 2014).

This report of gross failure is still perhaps somewhat superficial. Possibly the psychologists had small numbers to work with and/or were poorly-equipped to deal some of the statistical aspects of their work. More significant appraisals appear to have come from geneticists.

Along those lines in September 2008, the geneticist David Goldstein (then at Duke University) was quoted regarding the outcome of thorough (or "tour de force") comparisons between the million or so common genetic variations and the inheritance patterns associated with the occurrences of common complex diseases (which overlap into the behavioral domain too) (Wade, 2008). Goldstein pointed out that:

[a]fter doing comprehensive studies for common diseases, we can explain only a few percent of the genetic component of most of these traits. For schizophrenia and bipolar disorder, we get almost nothing; for Type 2 diabetes, 20 variants, but they explain only 2 to 3 percent of familial clustering, and so on.

Goldstein then added:

It's an astounding thing that we have cracked open the human genome and can look at the entire complement of common genetic variants, and what do we find? Almost nothing. That is absolutely beyond belief. 
Of note is that "common" here implies that a given DNA code variation is present in at least 5 percent of humans. This initial and under-appreciated failure of genetics - in particular the common variants hypothesis in which commonly occurring variations in our DNA were hypothesized to be correlated with common variations in individual outcomes-has been followed by about a decade of mostly awkward silence. This missing heritability (or more tangibly the missing headline) problem is a very big deal.

The above "beyond belief" quote and position were reiterated in a subsequent 2010 Scientific American article, "Revolution Postponed" (Hall, 2010). Another frank appraisal also came in 2010 in which Jonathan Latham and Allison Wilson of the Bioscience Resource Project pointed out that with few exceptions (including previously identified genes for cystic fibrosis, sickle cell anemia, and Huntington's disease; and also including genetic contributions for some instances of Alzhemier's and breast cancer):

according to the best available data, genetic predispositions (i.e. causes) have a negligible role in heart disease, cancer, stroke, autoimmune diseases, obesity, autism, Parkinson's disease, depression, schizophrenia and many other common mental and physical illnesses that are the major killers in Western countries (Latham \& Wilson, 2010).

They went on to ask (in italics) "[h] ow likely is it that a quantity of genetic variation that could only be called enormous (i.e. more than $90 \%-95 \%$ of that for 80 human diseases) is all hiding in what until now [circa 2010] had been considered genetically unlikely places?".

The latest and thus most significant appraisal showed up in a May 2017 Scientific American article, “Schizophrenia's Unyielding Mysteries: Gene Studies Were Supposed to Reveal the Disorder's Roots. That Didn't Happen. Now Scientists Are Broadening the Search" (Balter, 2017). The author Balter described the big DNA search tool utilized, Genome Wide Assessment Studies or GWAS, as:

scan[ning] the entire genome for differences between the disease and control groups. [They] employ sophisticated statistical analyses to pick up even small increases in the number of specific genetic variants that might contribute to disease risk.

These searches very carefully check for statistical connections between variations in DNA and the occurrences of heritable conditions like schizophrenia.

These big schizophrenia DNA searches as of 2017 involved a scientific armada numbering over 800 researchers and DNA samples from more than 900,000 subjects. Balter provided a number of deceptively positive reports before offering the bio-skinny. In one such sober assessment David Goldstein, currently director of Columbia University's Institute for Genomic Medicine, commented that the C4 finding and the associated possible insight for schizophrenia represents "the first time we have gotten what we wanted out of a GWAS." Additionally, the C4 
finding was characterized by one researcher, Kenneth Weiss (an evolutionary geneticist at Pennsylvania State University) in diminutive fashion- "[e]ven if the C4 story is right, it accounts for only a trivial amount of schizophrenia” and that its significance "is debatable".

Another fitting (and ironic) assessment came from the behavioral geneticist, Eric Turkheimer, who said that "GWAS shows that schizophrenia is so highly, radically polygenic [i.e., with many DNA contributors] that there may well be nothing to find, just a general unspecifiable genetic background". Effectively, "we know that the DNA roots are there, but we just can't find them". Finally, David Goldstein provided a appropriate critical comment on the nature of the search business in saying that "[p]eople working in the schizophrenia genetics field have greatly over-interpreted their results" and further that they should utilize "a whole lot more humility". Is there any part of the genomic search business where this comment does not apply?

\section{Conclusions}

In Ernst Mayr's What Evolution Is readers can find a finely written synopsis of the scientific understanding of evolution. Mayr's synopsis highlights two scientific assumptions about evolution. The first is the somewhat subtle one that evolutionary processes simply reflect physics-dictated phenomena, with no underlying direction. Mayr offers some defense of this assumption, whilst others have questioned it. The second and more significant assumption is that DNA is capable of fulfilling its evolutionary roles. Mayr doesn't even acknowledge this assumption and apparently few even now dare question it.

Mayr's confidence is unfortunately reflected in the response to the 2016 book by Siddartha Mukherjee, The Gene. Mukherjee's book captured the unquestioned materialist-jist of modern genetics with its presumed DNA support. The book was highly praised and as far as I could tell the underlying genetic/materialist logic never questioned. This was true even amongst the hundreds of Amazon comments that I scanned (although a few noted on how poorly written the book was). Other than arguably in a paragraph on page 487, the book never hints at the unfolding failure of the genetic searches.

The deeper intellectual point here is that embedded in the mystery of the origins of the heritable components of humanity's disease susceptibilities and behavioral tendencies, is a big question mark for presumed architect of life-materialist-beget evolution. These heritable phenomena are supposed to be specified for by DNA, as of course are the many innate aspects of life. I think that it is likely that the expectations of personal genomics and behavioral genetics will ultimately fail in a big way. If the origins of our individual behavioral inclinations are not given by DNA, then how much confidence should we have in a DNA basis for the species- or gender-specific behavioral tendencies, as presumed by evolutionary psychology? Innate behavioral differences should be specified via the DNA, whether they occur between two individuals or more generally be- 
tween two species.

If the missing heritability problem continues to hold then what does that suggest with regards to science's certainty that underneath it all is simply physics (and ultimately, of course, equations (Carroll, 2016))? It is perhaps noteworthy that such a failure would appear to be consistent with the suggestion offered by the (Nobel laureate) physicist Eugene Wigner about a possible contradiction between the "laws of heredity and of physics" (Wigner, 1960).

Rejecting the possibility that homo sapiens are exceptions to the laws of inheritance (and apparently physics), what are you left with? Only insiders could provide insight into the remaining conceivable ways that the genomic searches could ultimately prove successful. Any such possible resolution would seem likely to include some kind of significant reassessment of the workings of natural selection, which are typically described as "simplicity itself” (Orr, 2009).

I suggest that science has been far too certain of its vision of life. At no point in Mayr's What Evolution Isis there any hint of doubt in materialism.

For those wondering about religious perspectives, I can not imagine a more significant mystery. In other works I have explored the possible fit of a reincarnation-based process for this situation (Christopher, 2017a; Christopher, 2017b). Moreover, people should be considering alternative explanations to science's materialism and its workhorse, DNA. Religions could have been on to something with their non-materialist beliefs about top-down contributions to life (from God/gods), and/or bottom-up contributions (from souls).

Heritability represents profound mysteries and simply ceding authority to science is not a smart move.

\section{Conflicts of Interest}

The author declares no conflicts of interest regarding the publication of this paper.

\section{References}

Balter, M. (2017). Schizophrenia's Unyielding Mysteries. Scientific American, May 2017.

Carroll, S. (2016). The Big Picture: On the Origins of Life, Meaning, and the Universe Itself. New York, NY: Dutton.

Christopher, T. (2017a). Science's Big Problem, Reincarnation's Big Potential, and Buddhists' Profound Embarrassment. Religions, 8, 155.

http://www.mdpi.com/2077-1444/8/8/155

Christopher, T. (2017b). A Hole in Science: An Opening for an Alternative Understanding of Life (Expanded Third Edition).

https://www.amazon.com/Hole-Science-Opening-Alternative-Understanding/dp/1629 $670693 /$

Collins, F. (2010). The Language of Life: DNA and the Revolution in Personalized Medicine. New York, NY: HarperCollins.

Fromme, P., \& Spence, J. C. H. (2017). Split-Second Reactions. Scientific American, 316, 62-67. https://doi.org/10.1038/scientificamerican0517-62 
Green, E. D. (2013). Human Genome, Then and Now. New York Times, 15 April 2013.

Hall, S. S. (2010). Revolution Postponed. Scientific American, 303, 60-67. https://doi.org/10.1038/scientificamerican1010-60

Horgan, J. (2014).

http://blogs.scientificamerican.com/cross-check/2014/10/14/quest-for-intelligence-gen es-churns-out-more-dubious-results/

Kingsley, D. M. (2009). From Atoms to Traits. Scientific American, 300, 52-59. https://doi.org/10.1038/scientificamerican0109-52

Landau, E. (2009). Born in Male Body, Jenny Knew Early that She Was a Girl. CNN, 14 June 2009. http://edition.cnn.com/2009/HEALTH/06/12/sex.change.gender.transition/

Latham, J., \& Wilson, A. (2010). The Great DNA Data Deficit: Are Genes for Disease a Mirage? http://www.independentsciencenews.org/health/the-great-dna-data-deficit/

Lewin, R. (1980). Is Your Brain Really Necessary? Science, 210, 1232-1234.

http://www.rifters.com/real/articles/Science_No-Brain.pdf https://doi.org/10.1126/science.7434023

Mayr, E. (2001). What Evolution Is. New York, NY: Basic Books.

Mukherjee, S. (2016). The Gene: An Intimate History. New York, NY: Scribner.

Orr, H. A. (2009). Testing Natural Selection. Scientific American, 300, 44-51. https://doi.org/10.1038/scientificamerican0109-44

Pinker, S. (2002). Blank Slate: The Modern Denial of Human Nature. New York, NY: Viking.

Schafer, A. (2006). https://genetics.thetech.org/ask/ask166

Sheldrake, R. (2012). Science Set Free: 10 Paths to New Discovery. New York, NY: Deepak Chopra Books.

Solomon, A. (2012). Far from the Tree. New York, NY: Scribner.

Venter, J. C. (2014). Life at the Speed of Light: From the Double Helix to the Dawn of Digital Life. New York, NY: Penguin Books.

Wade, N. (2008). A Dissenting Voice as the Genome Is Sifted to Fight Disease. New York Times, 16 September 2008.

Watson, J. D. (2003). A Conversation with James D. Watson. Scientific American, April 2003.

Wigner, E. (1960). The Unreasonable Effectiveness of Mathematics in the Natural Sciences. http://www.dartmouth.edu/ matc/MathDrama/reading/Wigner.html

Zimmer, C. (2015). Is Most of Our DNA Garbage? New York Times Magazine, 8 March 2015. 